\title{
Meaning and Egoism: Are the Notions Compatible?
}

\author{
Leonid Z. Levit (Corresponding author) \\ Centre for Psychological Health and Education \\ K. Marx Street 8-114, Minsk, 220030, Belarus \\ Tel: 375-173-278-304; E-mail: leolev44@tut.by
}

Received: October 29, 2013 Accepted: December 18, 2013 Published: January 11, 2014

doi:10.5296/ijssr.v2i1.4487

URL: http://dx.doi.org/10.5296/ijssr.v2i1.4487

\begin{abstract}
The author shares some results of his pioneering investigations in the specific sphere of positive psychology dealing with the connectedness between the "egoism" and the "meaning" concepts. The conclusions obtained provide more space for new advances and further specifications of the scientific landscape in the domain of meaningful and happy life achievement.
\end{abstract}

Keywords: egoism, personal uniqueness, meaning, happiness, eudaimonia, existentialism

\section{Some Preliminary Considerations}

At first glance, our present attempt to prove a kind of commonness or even kinship existing between the "egoism" and the "meaning" concepts may look odd if not ridiculous. My only justification lies in the fact of purely accidental discovery of strong correlations between the two scales identifying the corresponding notions in two ESM-investigations conducted in the years of 2011 - 2012. Therefore in this particular case all the "corroborating theory" appeared after experimental results had been obtained. Since the construction of this paper primarily reflects the chronology of the work accomplished and preserves inner logic of the developing ideas, it is far from being generally accepted. The results of our (Leonid Levit) research are absolutely unique since we haven't found any information in scientific literature concerning the positive relationship between the "egoism" and the "meaning' concepts.

\section{POCH: Introduction and Brief Explanation}

In the years 2006 - 2012 the author elaborated a synthesizing conception, which is based on the ideas of systemic approach and combines biological, psychological, social and spiritual 
(the highest) level of individual life and activity (see Figure 1). The results of our six-year work on the problem are summarized in several monographs (Levit, 2010, 2011a, 2011c, 2012a, 2013d) and plenty of articles (Levit, 2009-2013; Levit \& Radchikova, 2012a, b).

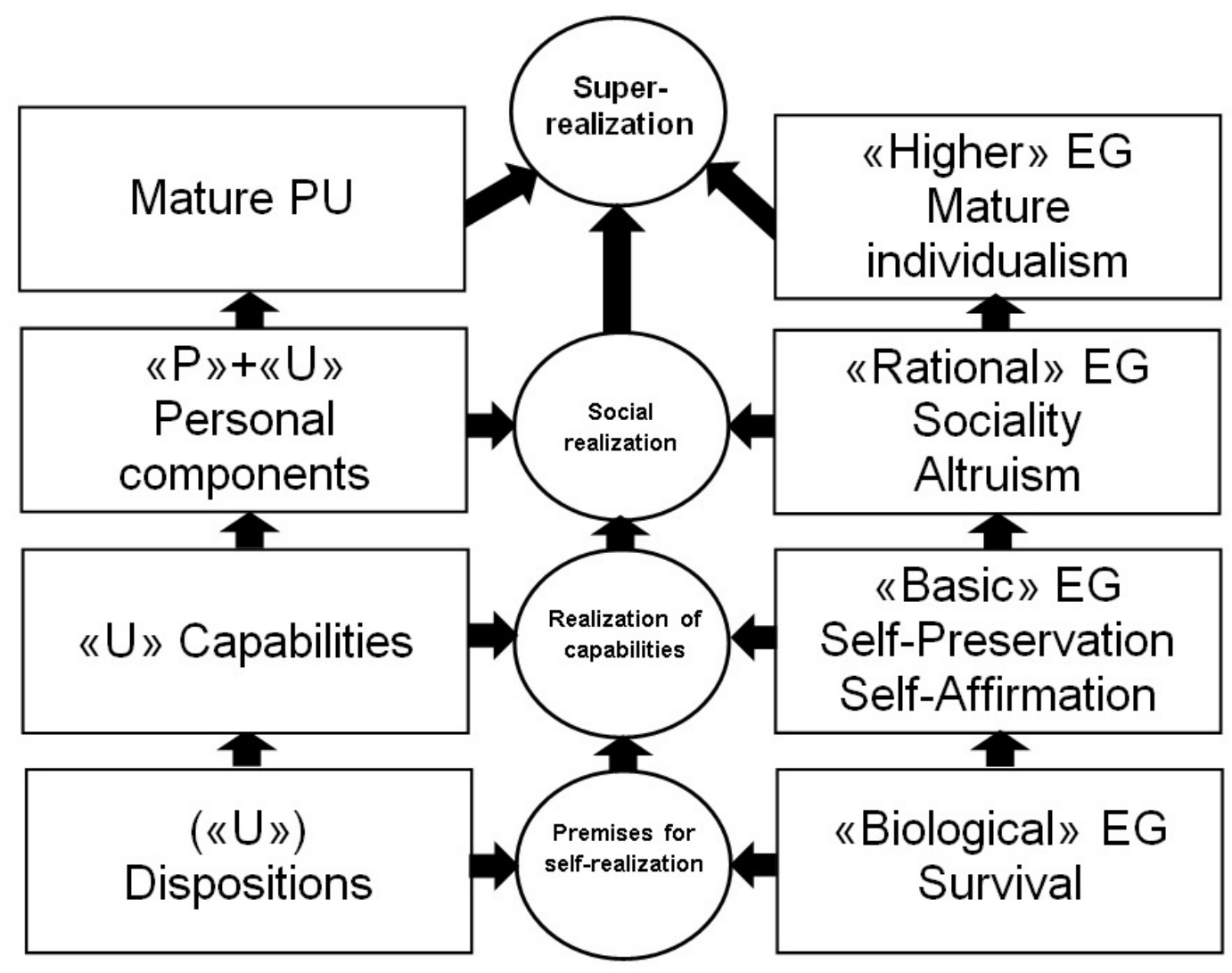

Figure 1. POCH

Our Person-oriented conception of happiness (POCH) belongs to eudaimonic group of theories, which deal with person's realization of her own unique potential (Ryan et al., 2008; Ryff \& Singer, 2006; Waterman et al., 2008). POCH represents the interaction of two systems - «Personal Uniqueness» (PU) and «Egoism» (EG). The original design of the new model was based on the necessity to discriminate the concepts belonging to substantial issues of self-realization (e. g. The Ancient Greek concept of daimon, the Jungian Self, the Inner Self of C. Rogers, the inner potential) and its more dynamic functional forces (the Maslowian self-actualization, Freud's sublimation etc.).

Moving bottom-up, let us briefly describe the main components of POCH. Each system consists of four levels. Both systems develop from one level to the higher one, thus changing the interaction of horizontally corresponding levels.

Firstly let's say some words about the Personal Uniqueness system (the left one). PU is somewhat analogous to daimon in its classical meaning or personal potential in humanistic comprehension. Personal Uniqueness represents synthesis of individual potentials, gifts and talents ("U") with the personal components ("P") that facilitate its application in appropriate 
activity (assurance, persistence, etc.). The latter ("P") rarely have an inborn character and are associated with an adult personality rather than the former ("U").

At its first biological level PU is represented by the letter «U» (Uniqueness), which implicates a kind of natural gift, the inherited disposition of individual. At the next, second level which is usually associated with person's youth, the disposition gradually changes into abilities and begins to actualize. At that very period, a young man usually has some difficulties due to the shortage of his personal maturity and responsibility. The situation is being corrected at the third stage, when the person acquires motivational components of self-regulation $(« \mathrm{P} »)$ which help to overcome the obstacles inside specific activity and persistently move towards the attainment of personal goals. At the final fourth stage (if it comes) we can see the mature Personal Uniqueness. Its realization provides all the eudaimonic effects including the meaningful life achievement.

Now let's describe the «Egoism» (EG) system. The biological («body») level of our model (EG-1) is represented by the concept of Health, which we understand primarily as the absence of essential body problems in the course of psychological self-realization. Originally, person's health furthered his survival in nature. The necessity of its inclusion is determined by the importance of biological, genetic premises of man's egoism as well as a number of works showing beneficial effects of person's health on her self-realization and happiness achievement (Diener \& Biswas-Diener, 2008; Myers, 2002; Waterman, 1984).

As for the concept of Basic Egoism (EG-2), the inborn property which is common to humans and other living creatures we place it at Level 2. EG-2 is responsible for self-protection and survival of species, for satisfying two basic instincts (the need for food and sexuality) that brings fundamental pleasures to an individual (Kringelbach \& Berridge, 2009).

Moving further up along the second level, EG-2 gradually transforms into Rational Egoism (REG), that includes intellectual, regulatory, and (if necessary) reflexive components. REG helps a person to achieve her own goals taking into consideration other people's interests. Until being reoriented towards PU actualization REG is responsible for "human" pleasures and social activity.

Finally, the fourth level is associated with higher forms of egoism (individualism), when a person, having surmounted the three previous stages, makes the deliberate decision to devote her life to unique self-realization, taking her Personal Uniqueness as the highest value (Levit, 2013c; Levit \& Radchikova, 2012a). Here we can see the overcoming of the lower, Basic Egoism with its pleasure principle and the serious reorientation of Rational Egoism on the third level. While REG organizes the social environment for an individual, her Higher Egoism of Level 4 creates the best conditions for the PU actualization.

Thus, we argue that cohesive interaction of EG-4 and PU-4 brings self-realization and complete human life. «Egoism» system at its higher levels is the best partner for «Personal Uniqueness» system since it accomplishes protective, intellectual and motivating functions in the process of its actualization.

Introducing our new conception we take into account, that positive psychology will hardly 
feel itself very convenient (at least at first) with such negatively loaded term as "egoism". So let's remind that REG (and then Higher EG) radically distinguish from Basic EG and even overcome it in the process of self-actualization. Can inborn egoism's negotiation and submission be called truly egoistic? Not likely.

Just in that area there appear motivation premises for eudaimonic life. The «Egoism» system comes in contact with the mature «Personal Uniqueness» system, the result of which is a new substance, which we call «Super-realization». Maslowian peak experience, the flow states of M. Csikszentmihalyi, Jungian individuation, contemporary and ancient theories of eudaimonia as well as some forms of person's unusual spiritual experience take place in it. The function of «Higher» Egoism still consists in its protective and motivation properties, which help an individual strive for peak level and transcend his limits.

We have elaborated and tested several techniques and inquiries based on our theoretical conception. Some of them connected to the given topic will be discussed below.

\section{ESM Investigations}

Our first research with the help of Experience sampling methods (ESM-1) was conducted in 2011 (Levit, 2012f; Levit \& Radchikova, 2012b). It was dealing with the study of the main concepts which are usually ascribed to eudaimonic and hedonic components of person's activity. In the next study (ESM-2) the form was broadened: besides some other objects it included the "meaning" and the "egoism" scales. The first one sounded like "My own choice", while the second - "Good, benefit for me" (opposite to the "altruistic" scale "Good, benefit for others"). In the ESM-3 investigation conducted in 2012 the "meaning" scale was given the more precise formulating: "Meets my values, has meaning for me" (Levit, 2013f).

\subsection{ESM: The Procedure}

Four persons took part in ESM-2; the same number participated in ESM-3. Four men and four women aged $25-52$, with higher education filled the form every 2 hours (when they were not sleeping) for two weeks. First of all the participants were given written instructions. They registered out the activity they were engaged in as well as their thoughts (in case the thoughts were not corresponding to what they were doing). They also evaluated (from 0 up to 10 points) each kind of activity according to 12 scales denoting the main concepts which are usually associated with the well-known theories of happiness and subjective well-being. ESM-2 also applied to pointing out the flow activities with the subsequent comparative analysis between the two groups of statistics. One of the participants in ESM-2 decided to fill the curtailed form (excluding the "egoism" scale) that didn't change the general regularities discovered.

\subsection{ESM: Brief Results}

The correlations between the "egoism" scale and the "meaning" scale in ESM-2 are as follows: 0,$45 ; 0,49 ; 0,04$. As one can see, all of them are positive. Besides, two out of three are statistically significant. The correlations between "egoism" and "meaning" became even higher in the activities associated with the flow states (according to the participants' reports 
made immediately after ESM-2 termination), namely 0,$53 ; 0,81 ; 0,51$ correspondingly. The factor analysis also displayed that both scales were related to one factor. We even thought as a joke that the "meaning" scale of ESM-2 "My own choice" could be renamed into "My own egoistic choice".

Even more unexpected data of ESM-3 have shown primarily strong correlations between the "egoism" and the "meaning" scales, namely: 0,$52 ; 0,75 ; 0,86 ; 0,93$. Only positive (though not always statistically significant) correlations were also discovered between the "egoism" and the "altruism" scales (Levit, 2013d; Levit \& Radchikova, 2012b). All the discovered regularities appear quite extraordinary.

It goes without saying we (L. L.) couldn't pass by the results obtained, though such topic was not the institutional aim of our investigations. So, our subsequent efforts were aimed at clarifying the possible resemblance between both (egoism and meaning) concepts.

\section{Meaning and Egoism: Comparative Analysis}

Inasmuch as I don't consider myself to be highly advanced expert in the sphere of meaning and existentialism as a whole, I turned to D. Leontjev's monograph "The Psychology of Meaning" (Leontjev, 2003) and some other scientific sources dealing with the item. My reading was biased: I searched and found some specific characteristics, descriptions and definitions of meaning which could be to some extent, more or less and even fully applied to the notion of egoism. Some results of my theoretical work can be seen below.

First of all let's give rather broad definition of egoism as person's preoccupation with his own interests and desires. His Ego is or should be the basis of his motivation and activity (Mosley, 2005). All the ultimate desires of an egoist are directed at himself. Therefore it is not surprising that such (egoistic) desires and corresponding activity can be perceived by a person as highly meaningful, while clarifying the resemblance between meaning and egoism becomes reasonable.

According to D. Leontjev, the notion of meaning helps to overcome some oppositions existing in psychology: between emotions and intelligence, between academic psychology and applied science. That's why the term "meaning" can acquire the higher methodological status, become one of the central notions (Leontjev, p. 14) and the ultimate category in psychology [ibid, p. 50]. In our opinion, all the abovementioned definitions can be referred to the notion of egoism as well since self-interest is often recognized as the basis of all people's activity. Speaking about polysemanticism of meaning (p. 74), we should keep in mind that egoism is no less polysemantic. For example, R. Baumeister and K. D. Vochs speak about different levels of meaning (Baumeister \& Vohs, 2001, p. 610) - as well as we do while describing "EG" system in POCH.

Within humanistic approach, finding the meaning in life is associated with person's potential for development, as a possibility (Leontjev, p. 114). In the frame of POCH the highest level of the "Egoism" system (mature individualism) facilitates one's individual potential and Personal Uniqueness. Besides, meaningful life is considered to be one of the main characteristics of eudaimonia - the full-fledged and happy being (Levit, 2013b, 2013 g; Ryan 
et al., 2008; Ryff \& Singer, 2006; Waterman et al., 2008).

According to V. Frankl, person's will to find and realize the meaning of her life represents inborn motivational tendency (Frankl, 1969). Egoism is also interpreted as inborn substance which furthers person's survival and determines her motivation to a great degree. It is important, in the Psychological egoism group of theories the term under consideration is treated as the only ultimate motivation giving birth to other, instrumental motives and values. $\mathrm{V}$. Frankl writes that finding the meaning represents person's life designation, while in POCH frame individual realization of her Personal Uniqueness with the help of Higher Egoism is the very fulfillment of her designation (Levit, 2009, 2011b, 2012c, 2013b).

\section{Egoism and Meaning: Moral Contradictions}

Still, finding similarities between the two notions may seem counterintuitive for some scientists. In our opinion, the roots of such attitude mostly belong to the sphere of morality. The term "meaning" is always treated positively while "egoism" has multiple negative implications. The contemporary positive psychology tries to avoid any allusions between person's egoism and her pursuit of happiness though such relationship is vivid for the researcher in the field (Levit, 2012g, 2013e). To compare both terms means for somebody the same as searching for kinship between an A-student and a hooligan, between Mozart and Saglieri.

Here are some confirmations to the above said. As A. Waterman notes in his "The Psychology of Individualism", "the pursuit of self-interest is thought to yield a sense of alienation through treating others as objects to be manipulated for personal ends... The claim that individualism eventually results in alienation is associated with both socialist and existential philosophy" (Waterman, 1984, p. 7). As P. Wong writes, "the existential perspective tends to focus on learning to live with the dark side of the human condition, such as suffering, meaninglessness, loneliness, and death, and creating meaning through one's courageous choices and creative actions... In contrast, positive psychology emphasizes positive experiences and emotions as the pillars of a worthwhile life" (Wong, 2012, p. 3).

The reader already knows that egoistic behavior may be (and quite reasonably usually is) associated with the individual pursuit of happiness - the main topic of positive psychology. But we should again emphasize that $\mathrm{POCH}$ points at different egoism levels, in which connection the higher ones greatly distinguish from the lower. In our opinion, people can't (and shouldn't) get rid of their egoism but they are able to make a choice in favor of its more advanced and mature forms connected to PU realization and meaningful life achievement.

Let's proceed with the analysis of theoretical contradictions existing between the two notions. O. Flanagan in his monograph (Flanagan, 2007) considers finding a meaning in a material world to be "the really hard problem". Again we can see the opposition between the "spiritual" (meaning) and the "material", with which people's egoism is usually associated.

Examples supporting any of the two abovementioned points of view may be easily multiplied. The "egoism shadow" reflected by the meaning can significantly change scientific landscape in the domains of existentialism, eudaimonia and positive psychology as a whole. That's why 
in March 2013 we conducted a series of experimental investigations on studying the correlations between the main concepts of POCH (Egoism, Personal Uniqueness) and the "meaning" notion.

\section{The Questionnaires' Description}

The "ELU Plus" questionnaire ("ELU" in Russian is the abbreviation of the first letters from "Egoism" and "Personal Uniqueness") represents the advanced modification of the "ZULUREG" and the "ELU" inquiries (Levit, 2012d, 2013e). It is based on POCH theoretical model (Levit, 2012b, 2012e, 2013a, 2013c) and consists of six scales which contain 127 statements (the answers "Right" or "Wrong"). Scales 1, 2, 3 and 4 measure four corresponding (biological, basic, social and higher) levels of the "Egoism" system. Scale 5 ("Mature PU") measures the fourth, highest level of the "Personal Uniqueness" system, while scale 6 ("Super-realization") represents the top synthesis of both systems and measures the degree of individual self-realization. Similar to its "predecessors", the ELU Plus inquiry was repeatedly tested.

The inquiry "Meaningful Life Orientations" [Leontjev, 2000] is the adapted version of the PIL ("Purpose in Life") test elaborated by J. Crumbaugh and L. Maholick. It is designed to measure basic concepts associated with meaning: life purposes, the process and the result of its achievement, the "self" locus and the "life" locus.

\subsection{The Contingent}

98 external students from two Minsk institutes aged from 21 to 47 (30 years average), 78 females and 20 males took part in our investigation. Each participant filled in both forms one after another. The inspection was anonymous; the students had to mention only their age and gender. The results of the research are represented in Table 1.

Table 1. The correlations between the "ELU Plus" and the "MLO" inquiries. The significant moderate correlations are printed in boldface; the significant weak correlations are printed in italic

\begin{tabular}{lllllll}
\hline & Biological & Basic & Social & Higher & Mature & Super-realization (6) \\
& EG $(1)$ & EG (2) & EG (3) & EG (4) & PU (5) & 0,08 \\
\hline Purposes & 0,27 & $\mathbf{- 0 , 3 1}$ & $-0,07$ & 0,18 & $\mathbf{0 , 3 0}$ & 0,12 \\
Process & $\mathbf{0 , 4 4}$ & $-0,25$ & $-0,18$ & 0,25 & $\mathbf{0 , 3 5}$ & 0,18 \\
Result & $\mathbf{0 , 3 5}$ & $-0,27$ & $-0,03$ & 0,23 & $\mathbf{0 , 3 2}$ & 0,23 \\
Locus of Self & $\mathbf{0 , 3 6}$ & $-0,20$ & $-0,05$ & 0,26 & $\mathbf{0 , 3 2}$ & 0,20 \\
Locus of Life & 0,25 & $-0,25$ & $-0,07$ & 0,18 & $\mathbf{0 , 3 0}$ & 0,23 \\
Aggregate result & $\mathbf{0 , 3 9}$ & $-0,29$ & $-0,11$ & 0,23 & $\mathbf{0 , 3 4}$ & \\
\hline
\end{tabular}

\subsection{Results}

The first unexpected outcome is the presence of numerous positive correlations between the meaning scales and the Biological Egoism scale - person's feeling of health which means the absence of "body" limitations in the process of self-realization. Therefore, one of the unusual 
(though not trivial as it may seem) results of our investigation is the justified assumption concerning the possibility of strengthening man's health as an "asymmetric" means of resistance to existential vacuum and loss of the sense of life. Thus the notion of meaning sides here with the positive aspects of human existence.

We can also see totally negative correlations (primarily meaningful) between the MLO scales and the Basic Egoism scale, which denotes egoism in its most standard, traditional interpretation - as person's will for the quickest promotion of her own interests and desires. The result obtained verifies the existing ideas concerning the opposition between the "materialistic" egoism and meaning.

Scale 3 of ELU Plus (Social EG) has no significant correlations with the meaning scales.

Scale 4 measuring Higher Egoism as well as scale 5 (Mature Personal Uniqueness) have many significant positive correlations with the MLO scales that tell us about the relationship between person's feeling of her unique potential actualization and the meaning disclosure.

At length scale 6 has two significant correlations with the meaning scales. Almost total absence of correlations of scale 6 with scales of some other inquiries previously used tells about certain uniqueness of the Super-realization concept.

\section{Discussion and Preliminary Conclusions}

The results demonstrate some important overlapping areas relating to the terms "meaning", "egoism" and "personal uniqueness". The connection between the first two notions is particularly interesting since it looks counterintuitive for any existential psychologist and disclaims the traditional widespread negative views on egoism. The "egoism-meaning" connection gets stronger in the situations and activities associated with high personal well-being, particularly in the flow states. And vice versa: person's desire to find meaning in life may strengthen her Higher Egoism and the inner sense of her Personal Uniqueness.

We have found several theoretical definitions which can be applied to both concepts under consideration. Most probably, inborn egoism is one of the meaning "predecessors" in the process of ontogenesis, while its higher forms directly participate in PU realization and meaning creation. Person's self-actualization achieved with the help of Higher Egoism as well as her health strengthening proved to be good prevention factors against loss of meaning in one's life. Both of the terms can give the same answer to the main existential question: "What does a man live for?" - "For himself".

Thus we can offer scientifically proved possibilities for finding meaning during typical existential crises when a person has to tolerate painful conditions of living and/or cope with her own negative states of mind caused by losses and other hurting events. Our ESM results suggest that the best choice for an individual to cope with such situations may be her engagement in some specific activity associated with his "good", "benefit for himself" and PU realization in a broad sense. Victor Frankl's working on his book in Nazi's concentration camp serves as a proper example.

There also exists the second part of the answer - what an individual shouldn't do in order not 
to lose meaning of his life. The straightforward pursuit of short-termed hedonic pleasures may (and really does) lead to an existential "dead end". And according to our results, "social" realization also can't be considered the best choice since it doesn't guarantee meaning disclosure.

At the same time it's not quite clear why do some psychologists prefer to connect meaning primarily to the negative aspects of living. By doing so, they supply with an extra work other scientists (like P. Wong) which are in their turn trying to unify the artificially separated parts. After all it looks quite natural when "good" and "benefit" in person's mind are linked to her "meaning" and "values", particularly, in specific activities aimed at self-realization.

It is hardly possible to find life situations in which beneficiary and useful actions were at the same time meaningless for a man (high egoism, low meaning). We do not include materialistic consumption and the straightforward pursuit of hedonistic pleasures into our list since we are not persuaded of their long-term "good". The latest one serves as an example of strong Basic Egoism (level 2 in $\mathrm{POCH}$ ) but has nothing in common with productive self-fulfillment and flourishing.

The reverse case (high meaning, low egoism) is also hard to imagine. For example, if I give some money to a beggar, I make (seemingly) the altruistic deed which can possess high meaning for me. But since my spirit grows as a result of charity, my motivation should be considered to be at least partially egoistic. Frankly speaking, I "use" the beggar to feel myself better. This is a typical example of the so-called hedonistic egoism (Levit, 2012g).

Anyway, in the context of self-actualization, eudaimonic activity and happiness achievement the two concepts do not contradict but finely supplement with each other.

The author sees only one but serious obstacle to practical fulfillment of the given considerations. First of all, a person has to invest a lot of efforts into the chosen activity in order to get benefit and a sense of meaning in it. As M. Csikszentmihalyi has found out, one of the necessary conditions for the flow achievement is a high level of the task difficulty and even higher skills of an actor (Csikszentmihalyi, 1993). Very bad news for numerous loafers and hedonists...

In any case the intermarriage between the two "global" concepts - meaning and egoism - has taken place. The meaning is "egoistical" one way or another, while the highest level of egoism is deeply "meaningful". The extraordinary "fruits" of such a union may prove exceptionally useful for future investigations and theorizing.

\section{References}

Baumeister, R.F., Vohs, K.D. (2001). The Pursuit of Meaningfulness in Life. In C. R. Snyder \& S. J. Lopez (eds), Handbook of Positive Psychology. Oxford: Oxford University Press.

Csikszentmihalyi, M. (1993). The Evolving Self. New York: Harper Perennial.

Diener, E., \& Biswas-Diener, R. (2008). Happiness. Malden: Blackwell Publishing. http://dx.doi.org/10.1002/9781444305159 
Flanagan, O. J. (2007). The Really Hard Problem. Cambridge, Massachussets: A Bradford Book.

Frankl, V. (1969). The Will to Meaning. New York: Plume.

Kringelbach, M. L., \& Berridge, K. C. (2010). The Functional Neuroanatomy of Pleasure and Happiness. Trends in Cognitive Sciences, 13(11), 479-488. http://dx.doi.org/10.1016/j.tics.2009.08.006

Leontjev, D. A. (2000). The Inquiry of Meaningful Life Orientations. Moscow: Smysl.

Leontjev, D. A. (2003). The Psychology of meaning. Moscow: Smysl.

Levit, L. Z. (2009). The Psychology of Happiness: "Monte Carlo" or "Father Carlo"? Psychotherapy \& Clinical Psychology, 2, 42.

Levit, L. Z. (2010). Happiness of the Mind-3 (3rd ed.). Minsk: Para la Oro.

Levit, L. Z. (2011a). Formula of Happiness. Minsk: Varaksin.

Levit, L. Z. (2011b). The Psychology of Happiness: the Possibility of a New Paradigm. In S. I. Kudinov (ed.). Actual Problems of Ethnic and Social Psychology (pp. 319-323). Moscow: RUDN.

Levit, L. Z. (2011c). Person-Oriented Conception of Happiness: Life in the Name of Oneself. Minsk: Varaksin.

Levit, L. Z. (2012a). POCH: Between Freud, Jung and Maslow. Minsk: Varaksin.

Levit, L. Z. (2012b). Person-Oriented Conception of Happiness: The Brief History. Psychology and Psychotechnics, 8, 78-86.

Levit, L. Z. (2012c). Personal Uniqueness Therapy: the Theoretical Foundation of the Project. Tendencies and Innovations in Contemporary Science. The Materials of the 3rd Scientific-Practical Conference (the reports) (p. 47). Krasnodar.

Levit, L. Z. (2012d). Person-Oriented Conception of Happiness and the «Zulureg Inquiry». Vestnik Obrazovanija i Nauki. Pedagogika. Psihologija. Medicina, 2(4), 38-48.

Levit, L. Z. (2012e). Happiness: Person-Oriented Conception. International Journal of Advances in Psychology, 1(3), 46-57.

Levit, L. Z. (2012f). The Investigation of the Components of «Eudaimonia», «the Flow», «Happiness» and «Unhappiness» with ESM Techniques. Vestnik Obrazovanija i Nauki. Pedagogika. Psihologija. Medicina, 4(6), 22-50.

Levit, L. Z. (2012g). Happiness, Egoism, Altruism: Paradoxes of Interaction. Scientific-Practical Journal "Psychology. Sociology. Pedagogics”, 7, 10-19.

Levit, L. Z., \& Radchikova, N. P. (2012a). Person-Oriented Conception of Happiness: Theory and Practice (part 1). The National Psychological Journal, 7, 10-19.

Levit, L. Z., \& Radchikova, N. P. (2012b). The Use of ESM Techniques in the Explorations of Eudaimonic and Hedonistic Components of Personal Well-Being. // In A. V. Barabanschikov (ed.), Experimental Method in the Structure of Psychological Knowledge (pp. 368-373). Moscow: The Institute of Psychology of the Russian Academy of Sciences. 
Levit, L. Z. (2013a). Person-Oriented Conception of Happiness: Between Freud, Jung and Maslow. International Journal of Economy, Management and Social Sciences, 2(8), 576-584.

Levit, L. Z. (2013b). Training and Diagnostics of Individual Eudaimonic Activity Components. Actual problems of the humanitarian, social and economic sciences. Materials of the $7^{\text {th }}$ scientific and practical conference. Part 2. Saratov-Volsk: Nauka (pp. 72-79).

Levit, L. Z. (2013c). Person-Oriented Conception of Happiness: New Systemic Paradigm. Pedagogical Education in Russia, 1, 102-111.

Levit, L. Z. (2013d). Unique Potential, Self-Realization, Happiness. Saarbrucken: Lambert Academic Publishing.

Levit, L. Z. (2013e). Egoism, Personal Uniqueness, Narcissism: Common and Different Features. Pedagogical Education in Russia, 4, 212-225.

Levit, L. Z. (2013f). Are meaning and egoism compatible? In The Materials of the $5^{\text {th }}$ Russian Scientific Conference on Existential Psychology (the reports) (pp. 90-93). Moscow: Smysl.

Levit, L. Z. (2013g). Eudaimonia: Life for a Hero. Modern Foreign Psychology, 1, 69-77.

Mosley, A. (2005). Egoism. Ethics, Mind and Cognitive Science. Originally published: August 7 (pp. 1-7).

Myers, D. G. (2002). The Pursuit of Happiness. USA: Quill.

Ryan, R. M., Huta, V., \& Deci, E. L. (2008). Living Well: A Self-determination Theory Perspective on Eudaimonia. Journal of Happiness Studies, 9, 139-170. http://dx.doi.org/10.1007/s10902-006-9023-4

Ryff, C. D., \& Singer, B. H. (2006). Know Thyself and Become What You Are: A eudaimonic Approach to Psychological Well-Being. Journal of Happiness Studies, 9, 13-39. http://dx.doi.org/10.1007/s10902-006-9019-0

Waterman, A. S. (1984). The Psychology of Individualism. New York: Praeger.

Waterman, A. S., Schwartz, S. J., \& Conti, R. (2008). The Implications of Two Conceptions of Happiness (Hedonic Enjoyment and Eudaimonia) for the Understanding of Intrinsic $\begin{array}{lllll}\text { Motivation. Journal of Happiness } & \text { Studies, } & \text { 9, }\end{array}$ http://dx.doi.org/10.1007/s10902-006-9020-7

Wong, P. T. P. (2012). Toward a Dual-Systems Model of What Makes Life Worth Living. The Human Quest for Meaning (2nd ed., pp. 3-22). New York: Routledge.

\section{Copyright Disclaimer}

Copyright reserved by the author(s).

This article is an open-access article distributed under the terms and conditions of the Creative Commons Attribution license (http://creativecommons.org/licenses/by/3.0/). 